\title{
Ependymoma: lessons from the past, prospects for the future
}

\section{Reply to the letter by E. Bouffet et al.}

\author{
Charles Teo $\cdot$ Andrew Little
}

Received: 7 May 2009 / Published online: 3 July 2009

(C) Springer-Verlag 2009

\section{Dear Editor:}

We read with interest the letter by Bouffet et al. on our article "The management of completely resected childhood intracranial ependymoma: the argument for observation only" [1]. We would like to respond to several comments. We agree that further work is necessary to determine which patients are at low risk for recurrence. Molecular markers may ultimately prove useful. While hTERT is an intriguing candidate in post hoc analyses, its value for stratifying treatment in a prospective manner has not yet been demonstrated. We look forward to these studies. The best (though limited) definition of low risk currently in clinical practice is low-grade pathology in a child older than 3 years and no residual tumor on postoperative magnetic resonance imaging.

We were concerned with Professor Bouffet's assertion that our decision-making process is "arbitrary" and "hazardous" when, in fact, it has been refined by the senior author during his two decades of treating childhood ependymoma. We have acknowledged the preliminary nature of the data supporting observation as a treatment option, and we trust that our colleagues recognize the data's limitations; the implication that our oncology colleagues will consider our review a treatment guideline and not consider the benefits and risks of adjuvant radiation is worrisome. We assure Professor Bouffet that we have our patient's best interests at heart when we carefully select low-risk patients to avoid the toxicity of radiotherapy in the developing brain.

\section{Reference}

1. Little AS, Sheean T, Manoharan R, Darbar A, Teo C (2009) The management of completely resected childhood intracranial ependymoma: the argument for observation only. Childs Nerv Syst 25: $281-284$

C. Teo $(\square)$

Centre for Minimally Invasive Neurosurgery,

Prince of Wales Private Hospital,

Barker Street,

Randwick NSW 2031, Australia

e-mail: charlie@neuroendoscopy.info

A. Little

Barrow Neurological Institute,

Phoenix, AZ, USA 